\title{
CONSIDERAÇÕES SOBRE O CONJUNTO VAZIO À LUZ DA DEFINIÇÃO DE INCLUSÃO ENTRE CONJUNTOS
}

\section{ARTIGO ORIGINAL}

PEREIRA, Olavo de Carvalho ${ }^{1}$

PEREIRA, Olavo de Carvalho. Considerações sobre o conjunto vazio à luz da definição de inclusão entre conjuntos. Revista Científica Multidisciplinar Núcleo do Conhecimento. Ano 05, Ed. 01, Vol. 01, pp. 39-45. Janeiro de 2020. ISSN: 2448-0959, Link de acesso: https://www.nucleodoconhecimento.com.br/matematica/conjunto$\underline{\text { vazio }}$

\section{RESUMO}

O artigo analisa o conjunto vazio do ponto de vista de sua inclusão em qualquer conjunto que possui elemento, chegando a conclusão divergente do estabelecido, isto é, que o conjunto vazio não pode estar contido em nenhum conjunto que possui elementos.

Palavras-Chave: Conjunto vazio, teoria de conjunto.

\section{INTRODUÇÃO}

O presente artigo tem o objetivo de rever a afirmação de que o conjunto vazio é subconjunto de qualquer conjunto que possui elemento, à luz do que se depreende de definições contidas na teoria de conjuntos, no intuito de estabelecer sua formulação correta, apontando a real situação a ser considerada.

${ }^{1}$ Graduação - Bacharelado Em Matemática pela Universidade de Brasília. 


\subsection{CONJUNTO VAZIO}

Antes de iniciar com as definições que constarão desse artigo, ressaltamos que todas elas, assim como a teoria aqui exposta, têm idêntica redação nos livros de Giovanni e Bonjorno (2005), Lima (1978), Dante (2011) bem como lezzi e Murakami (1991):

"Chama-se conjunto vazio aquele que não possui elemento algum. O símbolo usual para o conjunto vazio é $\varnothing$. Obtemos um conjunto vazio quando descrevemos um conjunto através de uma propriedade $\mathbf{P}$ logicamente falsa. (p. 22A)"

De acordo com o atual ensino da matemática, aqui no Brasil, o conjunto vazio, que é o conjunto que não possui elemento algum, está contido em qualquer conjunto que possui elemento $(\varnothing \subset A$, qualquer que seja o conjunto $A$ ).

$A$ relação de inclusão afirma que um conjunto $A$ está contido em um conjunto $B(A \subset B)$ quando todos os elementos de $A$ são também elementos de $B$, isto é, quando $A$ é subconjunto de $B$.

Exemplo: seja $A=\{a, b, c\}$ e $B=\{a, b, c, d, e\}$

Os elementos de A são a, b e c;

Os elementos de B são a, b, c, d e e;

Vemos que os elementos de A - a, b e c- são elementos de B. Mas, não é só isso, observamos que alguns elementos de B - a, b e c- são elementos de $A$.

Concluindo: Se $A \subset B$, então A e B possuem elemento em comum, no exemplo dado, os elementos $a, b$ e c que são elementos de $A$ e de $B$, ao mesmo tempo.

Da definição de inclusão podemos concluir que, se todos os elementos de A são elementos de $B$, então algum ou alguns elementos de $B$ são elementos de $A$ (precisamente aqueles elementos de $B$ que são também os elementos de $A$ ). 
Conclusão: para haver inclusão de um conjunto $A$ em um conjunto $B$ é necessário que ambos tenham elemento ou elementos em comum (na verdade, $A$ e $B$ devem ter todos os elementos de A em comum).

Observamos que a definição de inclusão entre conjuntos "exige" que os mesmos possuam elemento.

Reforçando: se $A$ está contido em $B(A \subset B)$, então $A$ e $B$ possuem elemento em comum.

Usando a definição de inclusão sobre o conjunto vazio, concluímos que o mesmo não pode estar contido em nenhum conjunto que possui elemento, pois ele teria que ter algum elemento em comum com o conjunto no qual estivesse contido, o que não pode ocorrer pelo fato de não possuir qualquer elemento.

Conclusão: o conjunto vazio não pode estar contido em nenhum conjunto que possui elemento, isto é, o conjunto vazio não pode ser subconjunto de nenhum conjunto que possua elemento.

Reforçando: $\varnothing \not \subset A$, qualquer que seja $A \neq \varnothing$.

Os argumentos utilizados para justificar a posição vigente no ensino da matemática, além de não considerarem a consequência da definição de inclusão acima exposta, também não se sustentam com outros resultados decorrentes, também, das definições presentes na própria teoria de conjunto.

Abaixo, exporemos tais argumentos com a crítica correspondente.

Sabemos que um conjunto $A$, por mais que tenha elementos em comum com um conjunto $B$, se pelo menos um dos elementos de $A$ não pertence a $B$, dizemos que $A$ não está contido em $B$.

Exemplo: se $A=\{a, b, c, d, e\}$ e $B=\{a, b, c, d, f, g, h, i\}$ 
Os elementos de $\mathrm{A}$, exceto o elemento $e$, pertencem ao conjunto $\mathrm{B}$, por isto, neste caso, como um dos elementos de $A$ não pertence a $B$, temos que $A$ não está contido em $B(A \not \subset B)$.

Então, dados A e B conjuntos não vazios, se a resposta para a pergunta "existe algum elemento de A que não seja elemento de B?" for sim, concluímos que A não está contido em B; caso contrário, isto é, se a resposta for não, concluímos que todos os elementos de A são elementos de B e, neste caso, A está contido em B.

Usando a mesma expressão interrogativa, agora com o conjunto vazio, não podemos tirar as mesmas conclusões expostas, ou seja, se fizermos a pergunta "existe algum elemento do conjunto vazio que não seja elemento de B?" teremos "não" como resposta, simplesmente porque o conjunto vazio não possui elemento algum.

Este fato não pode jamais nos levar a concluir, como no caso acima em que ambos os conjuntos possuíam elementos, que todos os elementos do conjunto vazio são elementos do conjunto $B$, pois o conjunto vazio não possui elemento.

Poderíamos, também, fazer a seguinte pergunta: "existe algum elemento no conjunto vazio que seja elemento de B?"; como a resposta para essa pergunta também é negativa, podemos concluir, também neste caso, que o conjunto vazio não pode estar contido em B.

Aliás, pela própria definição de conjunto vazio, não podemos falar de elemento em relação a tal conjunto.

Interrogação como a que foi feita acima fica sem sentido quando relacionada ao conjunto vazio.

A rigor, a expressão "existe algum elemento do conjunto vazio que seja (ou não) elemento de B?" teria que ser dividida em duas partes: 1) "existe algum elemento do conjunto vazio" e 2) "que seja (ou não) elemento de B?". 
A resposta para a primeira parte 1) é não, uma vez que, em relação ao conjunto vazio, não podemos falar sobre elemento.

Respondida a primeira parte, a segunda fica sem sentido pois não podemos mais falar em "elemento".

Outra definição da teoria de conjunto diz que dois conjuntos A e B são disjuntos quando não possuem nenhum elemento em comum, isto é, quando a interseção entre $A$ e $B$ for igual ao Conjunto vazio:

Se $A \cap B=\varnothing$, então $A$ e $B$ são disjuntos.

Exemplo: $A=\{a, b, c\}$ e $B=\{d, e, f, g\}$

Vemos que A e B não possuem elemento em comum.

Isto significa que não pode haver relação de inclusão entre $A$ e $B$, melhor dizendo, $A$ não pode estar contido em $B$, nem $B$ pode estar contido em $A$.

Se $A \cap B=\varnothing \rightarrow A \not \subset B$ e $B \not \subset A$

Sabemos da teoria de conjunto que a interseção entre o conjunto vazio e um conjunto $B$, não vazio, qualquer é igual ao conjunto vazio.

$\varnothing \cap B=\varnothing$

A rigor, só deveríamos comparar conjunto que possui elemento com conjunto que possui elemento, e não conjunto que possui elemento com o conjunto vazio, que não possui elemento algum.

Então, a par da definição de conjuntos disjuntos, podemos afirmar que o conjunto vazio e o conjunto B são disjuntos. Isto significa, então, que o conjunto vazio não pode estar contido em $B$ pelo fato de não possuir nenhum elemento em comum com B.

Se $\varnothing \cap B=\varnothing \rightarrow \varnothing \not \subset B$ 


\section{Vemos assim que esta conclusão da própria teoria de conjunto embasa o fato de o conjunto vazio não poder ser subconjunto de nenhum conjunto que possui elemento.}

Vejamos agora o conjunto vazio sob outro ângulo, quando está contextualizado em um dado conjunto.

Do que foi visto acima, se $A$ e $B$ são conjuntos tais que $A \cap B=\varnothing$ e como $\varnothing \cap B=\varnothing$, podemos identificar o conjunto $A$ como um conjunto vazio para o conjunto $B$ e viceversa, no sentido especificado no exemplo abaixo em se tratando de conjuntos numéricos.

Exemplo. Se $A=\{a, b, c\}$ e $B=\{d, e, f, g\}$, como $A \cap B=\varnothing$, podemos dizer que $A$ é um conjunto vazio para $B$ e vice-versa, isto é, que os elementos do conjunto $A$ não pertencem ao conjunto $B$ e que os elementos do conjunto $B$ não pertencem ao conjunto $A, e$, por isso, se resolvermos uma equação no conjunto $A$ e obtermos como resultado um elemento do conjunto $B$, nesse caso $B$ seria um conjunto vazio para $A$, exatamente como descrito no exemplo a seguir com conjuntos numéricos.

Outro exemplo, se estamos trabalhando no conjunto dos números naturais, e, se o nosso contexto é o conjunto $\mathrm{N}$ e queremos resolver a equação $\mathrm{x}+5=0$, sabemos que a resposta -5 não pertence ao conjunto em questão. Então dizemos que a solução é vazia. Podemos então, sem prejuízo algum da lógica da definição de conjunto vazio, aplicada, no caso, ao contexto dos naturais, dizer que -5 pertence ao conjunto vazio.

Generalizando, qualquer número fora do contexto dos naturais será tido como pertencente ao conjunto vazio. Sendo assim, os inteiros negativos, os racionais e os irracionais, isto é, a união desses conjuntos formará o conjunto vazio dos naturais. Percebemos, assim, que o conjunto vazio, neste caso, no contexto dos números naturais, sob ótica de ser vazio pelo fato de não possuir nenhum elemento pertencente aos naturais, tem infinitos elementos. 
Se o contexto fosse o conjunto dos inteiros, o conjunto vazio das soluções seria a união dos racionais, exceto os inteiros, com os irracionais e teria, também neste caso, infinitos elementos.

$\mathrm{E}$ assim por diante, à medida que ampliamos o conjunto, o conjunto vazio correspondente é reduzido, até chegarmos ao conjunto dos complexos para o qual o conjunto vazio deve ser realmente vazio, não contendo nenhum elemento.

Agora, voltando ao exemplo dado, $x+5=0$, no conjunto dos naturais, tendo como resposta -5 pertencente ao vazio; se o conjunto vazio fosse subconjunto de qualquer conjunto, então -5 pertenceria aos naturais e, com isso, a solução não seria vazia, isto é, pertencente ao conjunto vazio.

Com isto queremos dizer que, se o conjunto vazio fosse subconjunto de algum conjunto, ele teria todos os seus "elementos" em comum com aquele conjunto, isto é, seus elementos pertenceriam àquele conjunto, e, com isso, ele não seria conjunto vazio.

\section{CONCLUSÃO}

No exposto mostramos que o conjunto vazio não está contido em nenhum conjunto que possui elemento.

A tese se baseou na própria teoria estabelecida, não se utilizando nada de estranho à mesma para justificá-la.

Relatamos tal observação na intenção de corrigir tópico que compõe os fundamentos da matemática, bem como para conferir consistência ao mesmo.

Os resultados decorrentes da presente conclusão devem ser reavaliados.

\section{REFERÊNCIAS}

DANTE, Luiz Roberto, Matemática, Volume Único, 2011. 
GIOVANNI, José Ruy e BONJORNO, José Roberto, Coleção Matemática Completa, 1ํㅗㄹ Série, Ensino Médio, 2005.

IEZZI, Gelson e MURAKAMI, Carlos, Fundamentos de Matemática Elementar, volume $1,1991$.

LIMA, Elon Lages. Curso de Análise, vol. 1, 1978.

Enviado: Novembro, 2019.

Aprovado: Janeiro, 2020. 